\section{Primary Hyperparathyroidism Presenting as Aneurysmal Bone Cyst of Tibia and Giant Cell Lesion of Mandible}

Sir,

Primary hyperparathyroidism (PHPT) is characterized by autonomous overproduction of parathyroid hormone (PTH) along with normal or high-normal serum calcium. It affects $1 \%$ of population and $85 \%$ cases are the result of a single parathyroid adenoma. Over-secretion of PTH may result in bone pains, progressive bone loss, pathologic fractures, bone tumors, renal calculi and proximal myopathy. 1,2 Several bone lesions, including metabolic disorders, may contain osteoclast rich giant cells. These lesions including giant cell tumors, aneurysmal bone cysts, and brown tumors of hyperparathyroidism have structural similarities. The most important functional similarity is their capability of bone resorption. ${ }^{1-3}$ In patients presenting with bone pains, weight loss, bone swellings or pathologic fractures, possibility of metastatic bone disease is often considered in the differential. Here, we report the case of a patient who was referred for skeletal scintigraphy, with clinical suspicion of metastatic bone disease.

A 36-year male presented with complaints of weight loss and severe bone pains for eight months. Six months ago, the patient had excision of painful aneurysmal bone cyst of left tibia and recently a mandibular swelling was excised which showed abundance of giant cells. Skeletal scintigraphy with Technetium-99m Methylene disphosphonate (99mTc-MDP) showed increased radiotracer uptake in calvaria, bilateral maxilla and mandible, costochondral junctions, multiple ribs, $10^{\text {th }}$ costo-vertebral junction, $5^{\text {th }}$ lumbar-vertebra, left tibia and appendicular skeleton (Figure 1). Bone scan findings raised clinical suspicion of metabolic bone disease; therefore, further workup was carried out which showed raised serum PTH (1412 pg/ml) (range: $10-69 \mathrm{pg} / \mathrm{ml})$ and serum calcium levels $(12.54 \mathrm{mg} / \mathrm{dl})$ (range: $8-10 \mathrm{mg} / \mathrm{dl})$. These were indicative of the presence of hyper-functioning parathyroid tissue. Dual-phase parathyroid scintigraphy with Technetium-99m Methoxy isobutyl isonitrile (99mTcMIBI) confirmed a parathyroid adenoma in lower half of left thyroid lobe (Figure 2 and 3). After left inferior parathyroidectomy, serum PTH $(50 \mathrm{pg} / \mathrm{ml})$ and serum calcium levels $(8.9 \mathrm{mg} / \mathrm{dl})$ returned to normal. Histopathology report confirmed the clinical diagnosis of parathyroid adenoma.
Giant cell lesions (brown tumors of hyperparathyroidism) are difficult to diagnose. They are not true tumors but result from excessive osteoclastic activity.2,4 For benign musculoskeletal pathology, hybrid imaging with single photon emission computed tomography and X-ray computed tomography (SPECT-CT) has been less frequently used. However, it not only improves the specificity of skeletal scintigraphy, but can also change the diagnostic category of some lesions. ${ }^{5}$ The radiologic similarities between brown tumors and other bone tumors, can make a definitive diagnosis difficult; and for this, SPECT-CT offers the unique opportunity to directly correlate the scintigraphic findings with $\mathrm{CT}$ images to

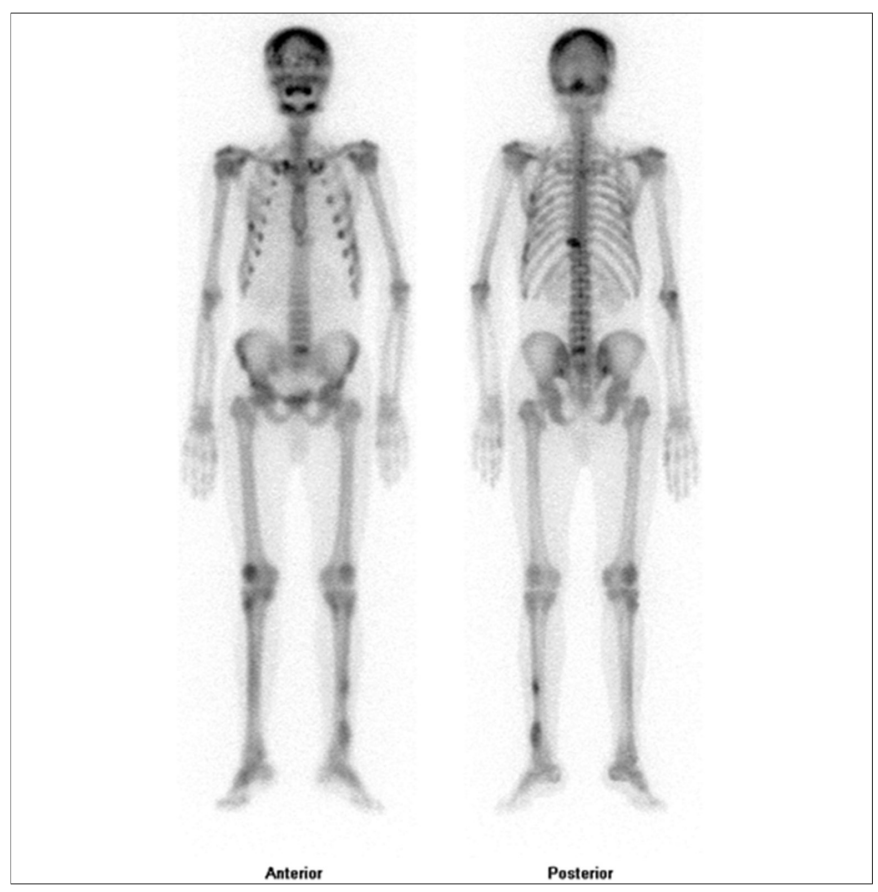

Figure 1: Bone scan performed with 99mTc-MDP shows multiple areas of abnormal and increased radiotracer uptake.

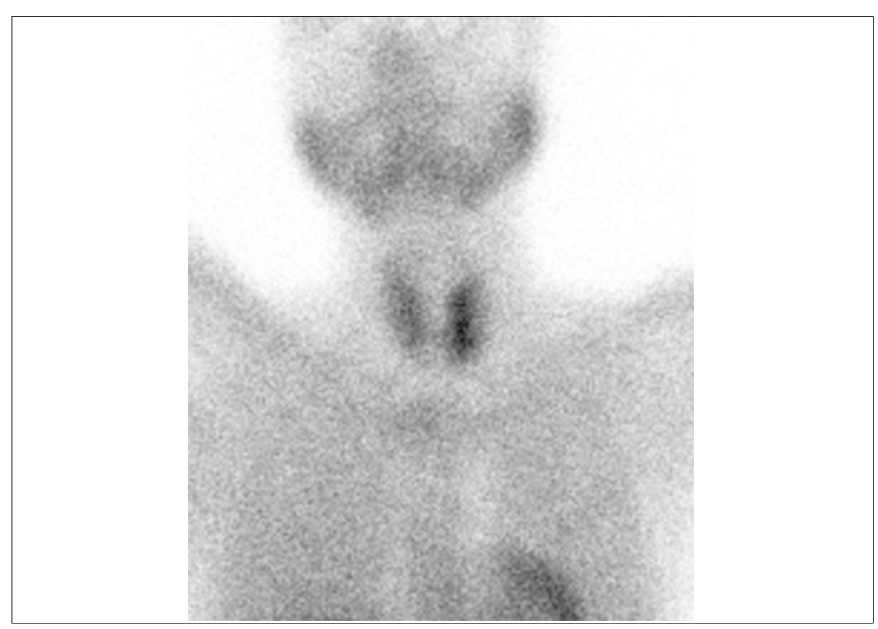

Figure 2: Anterior image of neck and chest at 15 minutes post-injection shows $99 \mathrm{mTC}-\mathrm{MIBI}$ uptake by both thyroid lobes. 


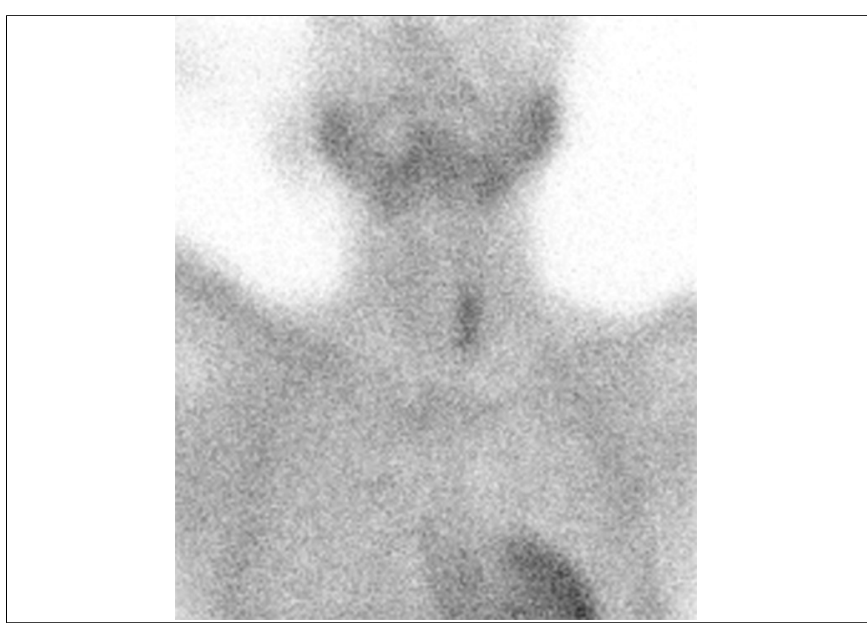

Figure 3: Anterior image of neck and chest at 2 hours post-injection shows washout of $99 \mathrm{mTc}-\mathrm{MIBI}$ from thyroid lobes with tracer retention only in the parathyroid adenoma, located in lower half of left thyroid lobe.

improve lesion classification.1-3,6 More recently hybrid positron emission tomography and X-ray computed tomography (PET-CT) imaging with F-18 FDG and F-18 $\mathrm{NaF}$ are also being used for detection of brown tumors in patients having osteolytic bone lesions with suspicion of metastatic bone disease. 7,8

Surgical excision of hyper-functioning parathyroid tissue has a cure rate of up to $98 \%$, as surgery results in regression of these brown tumors. Therefore, surgical excision is recommended for all patients clinically diagnosed with PHPT, and for minimally invasive surgery, preoperative functional imaging (parathyroid scintigraphy) and supporting anatomical imaging (ultrasound, CT or MRI) should be performed.1,4,9 In this regard, dual-phase parathyroid scintigraphy; as performed in our patient, has been found to be statistically superior to single-phase or dual-phase SPECT. However, combining early phase parathyroid SPECT-CT with dual-phase parathyroid scintigraphy increases the specificity for localization of parathyroid adenoma to $>96 \% .10,11 \mathrm{PET}-\mathrm{CT}$ parathyroid imaging with C-11 Methionine has also been used and shown more promising results than F-18 FDG. 12

This report emphasizes the importance of considering the possibility of metabolic bone disease in differential while investigating such patients. Hence, an array of investigations can be avoided which are usually performed during metastatic work-up.

\section{CONFLICT OF INTEREST:}

Authors declared no conflict of interest.

\section{AUTHORS' CONTRIBUTION:}

SZ: Conception, design and acquisition of study, research, analysis and drafting of manuscript, accountable for all aspects of the case report.

MR: Conception of study, critical revision for important intellectual content and final approval of the version to be published.

SS: Conception of study, critical revision for important intellectual content and final approval of the version to be published.

\section{REFERENCES}

1. John C, Kukora S, Zeiger M, Kleerekoper M, Pasieka J, Shaha A, et al. The American association of clinical endocrinologists and the American association of endocrine surgeons position statement on the diagnosis and management of primary hyperparathyroidism. Endocr Pract 2005; 11:49-54.

2. Sachin R, Vidya R, Sanjay B. Giant cell lesions associated with primary hyperparathyroidism. J Maxillofac Oral Surg 2015; 14: 930-4.

3. Werner M. Giant cell tumor of bone: Morphological, biological and histogenetical aspects. Int Orthop 2006; 30:484-9.

4. Fathima M, Pradeep B, Surjith V, Shree S, Asim B, Janis O. Primary hyperparathyroidism-related brown tumors mimicking other giant cell containing skeletal tumors: Role of correlative imaging in diagnosis. J Nucl Med Technol 2013; 41: 46-8.

5. Shouvik S, Burke C, Desai A, Vijayanathan S, Gnanasegaran G. SPECT-CT: Applications in musculoskeletal radiology. $\mathrm{Br} J$ Radiol 2013; 86:20120519.

6. Torsten K. Skeletal SPECT/CT: A review. Clin Transl Imag 2014; 2:505-17.

7. Sait S, Anar A, Metin H, Tulin O. Positron emission tomography/ computed tomography imaging of brown tumors mimicking multiple skeletal metastases in patient with primary hyperparathyroidism. Indian J Endocrinol Metab 2012; 16:850-2.

8. Aung Z, Carina M. NaF18-PET/CT Imaging of Secondary Hyperparathyroidism. Nucl Med Mol Imag 2015; 49:331-2.

9. Harvey Z, Janis $O$, James T, Frederic F. Endocrine system, In: Frederic $F$ (ed.) Nuclear Medicine - The requisites. 4th ed. Philadelphia: Elsevier saunders; 2014: p.90-7.

10. Lavely C, Goetze S, Friedman P, Leal P, Zhang Z, Garret E, et al. Comparison of SPECT/CT, SPECT, and planar imaging with single- and dual-phase $(99 \mathrm{~m})$ Tc-sestamibi parathyroid scintigraphy. J Nucl Med 2007; 48:1084-9.

11. Michele T, Melanie G, John L. Role of SPECT and SPECT/CT in the surgical treatment of primary hyperparathyroidism. Int $\mathrm{J}$ Mol Imag 2011; 141593

12. Alenezi S, Asa'ad S, Elgazzar A. Scintigraphic parathyroid imaging: Concepts and new developments. Dove Press Ltd. 2015; 5:9-18

Sabeen Zia, Mohammad Rauf and Shoab Shah

Department of Nuclear Medicine, Atomic Energy Cancer Hospital IRNUM, University Campus, Peshawar, Pakistan

Correspondence to: Dr. Sabeen Zia, Department of Nuclear Medicine, Atomic Energy Cancer Hospital IRNUM, University Campus, Peshawar, Pakistan

E-mail:sabinzia@gmail.com

Received: February 12, 2019; Revised: April 10, 2019;

Accepted: April 20, 2019

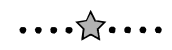

